\title{
Exciting KCL Alumni Weekend planned
}

King's College London Dental Alumni Association (KCLDAA) is holding an Alumni Weekend from 6-7 March 2020. The event will incorporate the John McLean Symposium on Friday 6 March, a Black Tie Dinner the same evening, and a Clinical Day on Saturday 7 March.

The John McLean Symposium will be held at Prospero House on Borough High Street from 09:30-17.00 and will feature (among others) Professor Mike Lewis speaking on oral medicine for practitioners; Dr Debora Reuss and Dr Jose Reuss speaking on clinical challenges in joint orthodontic/implant case care planning; and Dr Robert Oretti speaking on managing peri-implantitis the theory and the practice.

Alongside the dentist event will be a hygienists' and therapists' specialist section meeting from 13:00-17:00 at the Gordon Museum, Hodgkin Building.
A Staff and Alumni Drinks Reception and Annual Dental Dinner will take place at the Hilton Tower Hotel in London the same evening. During the dinner, KCLDAA will present awards in the categories of Single Tooth Restoration (to a student/DFT and to a young alumni); DFT Case presentation (to a DFT who completed training from 2018-2020) and for an essay competition (to a dental student or DFT).

On Saturday a Clinical Open Day will begin at 09:00 at Robens Suite in Guy's Tower, featuring two lectures followed by the DAA's AGM, a tour of the clinical teaching facilities, then the Dean's Lunch from 12:45-14:00.

In the afternoon, hands-on workshops are available for a limited number.

For more information and for full details of the programme, email kcldentalalumni@ gmail.com.

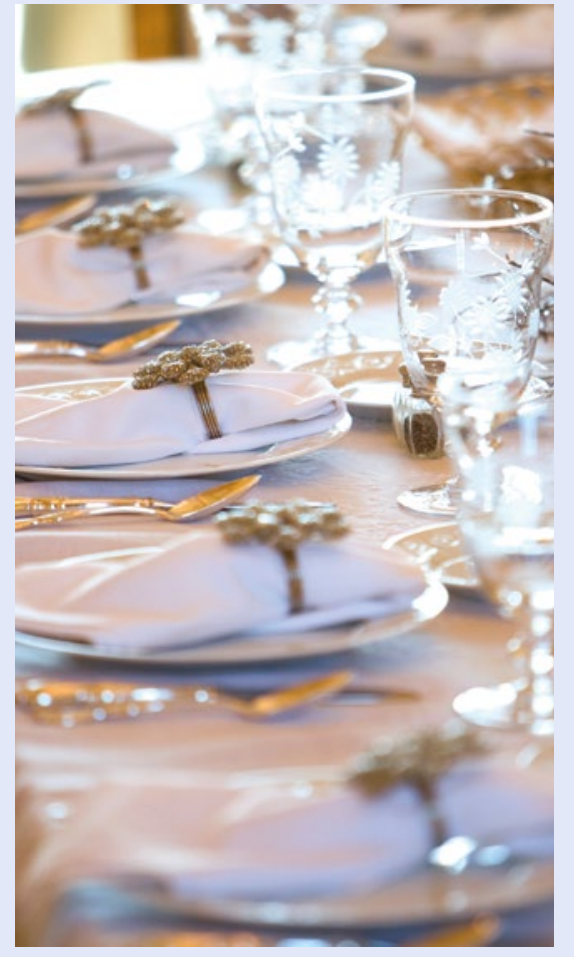

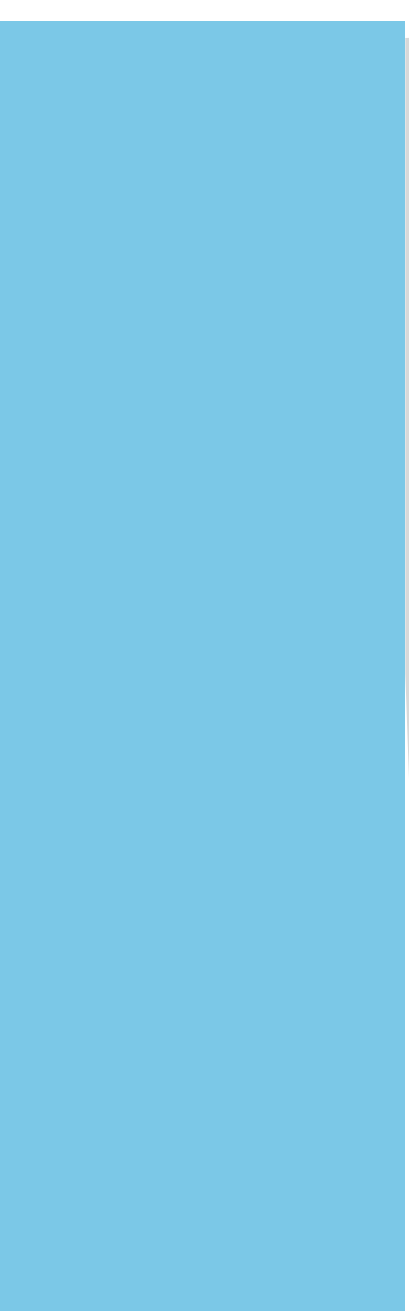

